DOI: 10.12957/demetra.2016.22502

\title{
A escolha pelo "Nada": reflexões psicanalíticas sobre a anorexia
}

\section{The choice of "Nothing": psychoanalytic reflections about anorexia}

\author{
Carolina Carvalho Dutral \\ Leticia Martins Balbi, ${ }^{12}$ \\ Cristiane Marques Seixas, 3 \\ ' Escola Letra Freudiana. Rio de Janeiro-RJ, \\ Brasil. \\ ${ }^{2}$ Universidade Federal Fluminense, \\ Departamento de Psicologia. Niterói-RJ, Brasil. \\ ${ }^{3}$ Universidade do Estado do Rio de Janeiro, \\ Instituto de Nutrição. Rio de Janeiro-RJ, Brasil. \\ Correspondência / Correspondence \\ Carolina Carvalho Dutra \\ linadutra@yahoo.com.br
}

\section{Resumo}

Este ensaio busca pensar o comportamento anoréxico como um sintoma presente em mulheres e homens jovens, a partir do caso de uma jovem no contexto da experiência clínica em psicanálise. Do ponto de vista psicanalítico, o comer "nada" do sintoma anoréxico pode ser situado de acordo com o que Lacan nomeia de "dialética da frustração", onde o objeto "nada" funciona como objeto de satisfação simbólica que opera uma separação em relação ao Outro. Nesse sentido, a dinâmica psíquica que se inscreve nesses casos diz respeito a uma satisfação pulsional que está colocada para ambos os sexos. Tendo em vista que essa dinâmica é estruturante para todos os sujeitos, considera-se que é a restituição de um lugar de fala, onde o sujeito construa novas barragens frente ao desejo insaciável do Outro, que indica uma possibilidade de tratamento dos sujeitos anoréxicos.

Palavras-chave: Anorexia. Psicanálise. Sintoma. Repulsa. Nada. Dialética da Frustração.

\section{Abstract}

This essay discusses the anorexic behavior as a symptom among young women and young men, based on the case of a young woman in the context of clinical experience in psychoanalysis. From the psychoanalytical point of view, eating "nothing" as an anorexic symptom can be situated as what Lacan refers to as dialectic of frustration, where the object "nothing" works as an object of symbolic satisfaction that separates the subject from the Other. In this sense, the psychological dynamic that falls within 
these cases is relative to the drive satisfaction that is faced by both sexes. By bearing in mind that this dynamic is structural for all subjects, one may consider that it is the recovery of a place for discourse, where subjects build new barriers to the insatiable desire of the Other. It indicates the possibility of treatment of anorexic individuals.

Key words: Anorexia. Psychoanalysis. Symptom. Repulse. Nothing. Dialectic of Frustration.

No contexto do mundo globalizado, em que a informação sobre os métodos para baixar o peso circula rapidamente pelas redes informacionais, cabe destacar que, para além do comportamento que tem por efeito o emagrecimento excessivo, articula-se uma sutil e grave dinâmica psíquica em que a comida, ou melhor, a ausência da comida, ganha um sentido erotizado. Numa cultura que valoriza exageradamente a magreza e vive o crescimento exacerbado de casos de obesidade, há que se interrogar como e por que, para alguns sujeitos, a anorexia apresenta-se como o sintoma por excelência.

Hoje em dia, encontramos em diversos blogs e comunidades virtuais, testemunhos e declarações de jovens anoréxicos e bulímicos colocando a céu aberto o alto grau de sofrimento ocasionado por essas condições corporais. Apesar da prevalência de casos em mulheres, temos acompanhado o aparecimento dos transtornos alimentares em homens. Segundo Almeida \& Guimarães, ${ }^{1}$ há vinte anos a proporção de homens com anorexia nervosa era de aproximadamente um para cada 20 mulheres, enquanto nos dias de hoje, esse número varia em torno de dez mulheres para cada homem.

Jade é uma jovem anoréxica que encontrou no site Pretty Thin um lugar onde pode expressar como se sente e ser apoiada por outras pessoas dessa comunidade. Aprendeu que não está sozinha e que outras pessoas sofrem da mesma desordem pelas mesmas razões. Esse site é, para Jade, um lugar seguro que lhe dá algo para fazer com seus dias, além de comer compulsivamente e vomitar. Brittney acha seu corpo disgusting e o site mostrou a ela que não está sozinha na sua fome de perfeição. Diz que isso lhe devolveu um senso de sanidade. Pela primeira vez na vida, foi capaz de se comunicar com uma comunidade de pessoas que viam a beleza nos seus olhos e entendiam seus métodos. Julie diz que seu peso domina sua vida: não há um dia em que não pense o quanto é imperfeita.

Freud, desde o Manuscrito $K^{2}$ até Moisés y la religión monoteísta, ${ }^{3}$ insistiu na tese de que o sintoma tem o caráter de uma formação de compromisso entre as representações recalcadas e as recalcadoras, substituindo uma lembrança patogênica. Com a introdução do ponto de vista 
pulsional, o sintoma passou a ser tomado como o resultado do conflito que se instaura no psiquismo entre uma tendência inconsciente que busca satisfação e outra consciente que é recalcada, sendo considerado como um substituto não mais da lembrança, mas da própria satisfação sexual. Frente às dificuldades clínicas impostas pela angústia e pela compulsão dos sintomas, Freud colocou, gradativamente, maior ênfase no aspecto econômico em jogo nos sintomas, em detrimento do aspecto dinâmico.

O presente trabalho busca articular as concepções freudianas sobre o sintoma anoréxico. Nesse sentido, traz relatos de uma mulher anoréxica, no contexto da experiência clínica em psicanálise, como ilustração da relação entre o sintoma anoréxico e a erotização da atividade oral, para refletir sobre os efeitos ocasionados pela abertura de um espaço de fala a partir da escuta psicanalítica. Além disso, trata-se aqui de contribuir para um entendimento mais amplo da anorexia, situando-a no campo da sexualidade com o intuito de lançar luzes sobre as questões de gênero na análise de temas que envolvem alimentação e cultura atualmente inscritas nessa problemática.

Tais questões apresentam-se associadas às exigências estéticas que ganham maior relevância na adolescência, mas acabam sendo vistas de forma naturalizada e determinista. Segundo Oliveira, nas relações de gênero que estão implicadas na anorexia, são reproduzidas expectativas dos papéis e dos lugares sociais dos homens e das mulheres na sociedade. "A referência aos músculos liga-se à ideia de força, enquanto componente essencialmente masculino. Em contraposição, a magreza associa-se às noções de delicadeza, fragilidade e feminilidade". ${ }^{4}$ Mas, indo além desta forma de entendimento, podemos agregar outras perspectivas fecundas na análise do fenômeno com a contribuição da psicanálise.

Para orientar inicialmente esse percurso, lembramos que a primeira definição de Freud para a anorexia está no Rascunho $G$, onde ele relacionou melancolia e anorexia, marcando a metáfora sintomática que aí se instituiu: a perda do apetite substitui e simboliza a perda da libido.

A famosa anorexia nervosa das moças jovens, segundo me parece (depois de cuidadosa observação), é uma melancolia em que a sexualidade não se desenvolveu. A paciente afirma que não se alimenta simplesmente porque não tem nenhum apetite; não há qualquer outro motivo. Perda do apetite: no sexual, perda da libido. ${ }^{5}$

Se a perda do apetite "simboliza" a perda de libido, então, apesar da gravidade que encontramos em muitos casos de anorexia, podemos encontrar também a possibilidade de sua articulação no trabalho simbólico das associações livres, restituindo o lugar de fala onde comparece o mutismo do sintoma.

No relato a seguir, destacam-se algumas falas recolhidas de uma jovem que a princípio poderia oscilar entre a bulimia e a anorexia, mas que nos faz pensar na face bulímica do sintoma anoréxico. Ao contrário de determinado grupo, identificado atualmente através de blogs e sites 
de relacionamentos que sustenta a anorexia como um estilo de vida, muitas pacientes apresentam um sofrimento em relação ao seu conflito com a comida. Se, por um lado, essas pacientes não legitimam seu projeto de restrição alimentar como aquelas que se filiam às comunidades Pró-Ana e Pró-Mia, por outro, oferecem este corpo magro como um cartão de visitas. Considera-se que esta posição paradoxal frente ao corpo e à alimentação configura um sintoma que é endereçado ao outro na busca de um tratamento.

Destacamos algumas falas de Laura, ${ }^{a}$ que foi diagnosticada pelos médicos como anoréxica, "problema" que, segundo ela, teve início na adolescência, após o falecimento da avó de quem cuidava. Como grande parte das jovens anoréxicas, Laura tem o estado geral debilitado, com movimentos lentos no caminhar e na gesticulação. Fala em um baixo tom de voz e seu discurso é interrompido por pausas, que ora são seguidas de uma tosse seca, ora de silêncio. Faz uso de medicações, porém as considera ineficazes, pois não a fazem comer mais nem tampouco impedem o refluxo do pouco que come. Após as pequenas refeições, vomita. Fala com naturalidade das suas frequentes internações hospitalares, cuja sequência revela o paradoxo do sintoma: se num momento liga para sua analista e demanda que não seja abandonada, em outro telefona em tom alegre, dizendo: "não precisa se preocupar comigo não, porque eu estou bem. Fiquei quatro dias na UTI, agora minha mãe está aqui comigo e está tudo bem”.

Algumas lembranças do passado devem ser destacadas, pois trazem de volta uma cena traumática na qual era abusada: "Tudo acontecia durante a noite e de manhã eu abria os olhos, chorava muito, sentia aquele repúdio...aquela repulsa. Depois ia pra escola e brincava”. Toda vez que visita os familiares, vomita muito.

Tendo em vista esse frequente retorno do vômito e sua associação à repulsa, Laura tem um hábito curioso: "se eu chupar uma bala, vomito. E eu chupo bala o dia todo. Chupando uma ou três, eu vomito do mesmo jeito". Podemos notar que a repetição do vômito é uma maneira de fazer retornar sua posição subjetiva aderida à cena traumática, uma atualização do sintoma que se funde ao eu.

Outra via associativa na determinação dos sintomas diz respeito às lembranças do período que ajudou sua comadre numa gravidez de alto risco, passando a cuidar do afilhado como se fosse seu próprio filho. Laura afirma que o menino precisava de cuidados especiais, pois "desde que nasceu teve um problema de refluxo; tudo o que comia, colocava pra fora, vomitava".

Da mesma maneira, a série significante repulsa-alimentação-refluxo se apresenta nas lembranças da época em que cuidava da avó doente: "éramos muitos netos, e nenhum quis aprender os procedimentos necessários. Eu era a única que fazia, três vezes ao dia”. Ela não

a Nome fictício de uma jovem anoréxica que nos permite reproduzir uma problemática frequente nesse grupo, para situar simbolicamente o conflito que se coloca por trás da relação problemática com a alimentação. 
economiza os pormenores desse procedimento, que incluía fazer curativos, trocar bolsas de colostomia, aplicar soro e remédios injetáveis, entre outros. Segue: "voltava da escola correndo, pra fazer tudo antes do almoço".

Numa sessão, chegou afirmando estar com "dormência no coração" e que seu médico determinou que interrompesse os atendimentos para se vincular a um tratamento de terapia cognitivo-comportamental. Quando questionada sobre o que achava desta decisão, falou: "Não sei. Vou aonde me levam".

A partir desse recorte das falas de Laura contextualizadas em sua história e aos momentos de sua análise, destacamos a repulsa, típica da histeria, como estando na origem do sintoma anoréxico que aí se produziu. Mas, neste caso, se a anorexia é, antes de tudo, um sintoma no sentido freudiano do termo, o que ele vem substituir e qual a satisfação que ele implica?

Na cena traumática pontuada por Laura, encontramos a manifestação da repulsa enquanto gozo que excede os limites do princípio do prazer e que vai ser deslocado para a atividade oral. A repulsa é efeito das lembranças de ser molestada, condensando a significação sexual da oralidade, que posteriormente, conecta-se com a função alimentar. Os sintomas de anorexia e vômito funcionam como substituto simbólico dessas lembranças infantis, associados com algumas identificações com outros personagens de sua história que também ficaram numa posição objetal, isto é, como objeto dos cuidados do Outro: sua avó, que precisava de seus cuidados na hora do almoço, e seu afilhado, a quem ajudara a cuidar dos problemas de refluxo.

No artigo A hereditariedade e a etiologia das neuroses, Freud ${ }^{6}$ afirma que no fundo da formação dos sintomas na histeria, encontra-se uma experiência traumática, de passividade sexual, anterior à puberdade, uma ocorrência sofrida com indiferença, indignação, susto ou até mesmo terror. Contudo, é na experiência de passividade que o sujeito é introduzido na sexualidade. Serge André afirma que a justificativa estrutural para o fato de Freud relacionar sempre essa descoberta do gozo sexual a uma experiência de sedução é que esse gozo é sempre antecipado, ou seja, a criança é inicialmente gozada pelo Outro, é um sujeito que se reduz a ser objeto do gozo do Outro. É a partir desta posição de objeto que se funda o trauma das neuroses.

Em Inibição, sintoma e angústia, Freud ${ }^{8}$ destaca outra função importante dos sintomas: na histeria é frequente que a formação de um sintoma seja uma forma de colocar fim à luta do eu contra um impulso pulsional desagradável, mas também ocorre o contrário, ou seja, dessa luta ser prolongada até se tornar uma luta contra o próprio sintoma. Freud afirma que os sintomas histéricos se revelam como um meio termo entre a necessidade de satisfação e a necessidade de punição: "o eu comporta-se como se fosse guiado pela seguinte consideração: o sintoma já está aí e não pode ser eliminado; agora se impõe aceitar essa situação e tirar dela o máximo proveito possível". ${ }^{9}$ No caso apresentado, a insistência de chupar bala mesmo sabendo que isso tem como consequência a permanência do vômito demonstra esse ganho do eu que se adapta ao sintoma 
para gozar de suas vantagens. Para Freud, o paradoxo do sintoma está no fato de que, ao ser encarregado de substituir importantes interesses, cobra um valor para sua afirmação, ou seja, ao se fusionar ao eu, se torna cada vez mais indispensável para este. ${ }^{10}$

O valor cobrado ao eu pelo sintoma anoréxico mostra bem a função desse ganho que Freud descobre no sintoma: há não só a satisfação advinda do compromisso entre as forças pulsionais e as forças do recalque; há também o gozo próprio da satisfação simbólica que envolve decepção e captura de um objeto vazio, e não simplesmente uma satisfação que diria respeito a uma suposta necessidade.

Essa é a ideia da satisfação simbólica advinda de uma fusão do sintoma ao eu que Lacan elabora no Seminário $4{ }^{11}$ Sua leitura enfatiza a importância de se distinguir, no campo das relações da criança com a mãe, os signos de amor - dons - marcados pela presença e ausência da mãe, e os objetos da necessidade, como o seio, por exemplo. A dialética entre esses objetos se dá de tal forma que, quando há uma frustração da criança em relação ao apelo de amor endereçado à mãe, esta frustração será compensada pela satisfação da necessidade. Ou seja, o leite é oferecido como compensação ao apelo que não pode ser atendido. Lacan afirma que a frustração não advém da recusa de um objeto de satisfação da necessidade, e sim da recusa do dom como signo do amor. Nas idas e vindas deste Fort- $D a^{\mathrm{b}}$ materno, o apelo se faz quando o objeto está ausente, mas quando este está presente, torna-se apenas símbolo do dom do amor - isto é, funciona como um "nada" em termos da satisfação. Não satisfaz o apelo de amor e instaura o circuito da insatisfação da demanda.

A satisfação simbólica é marcada, portanto, por seu caráter decepcionante - por conta da "dolorosa dialética do objeto, ao mesmo tempo ali e nunca ali"13 - e por isso vai ser substituída e compensada pela captura do objeto oral. Com isso, Lacan subverte e inverte a leitura biologizante da oralidade e da dialética da frustração: a satisfação simbólica, ou ainda, a in-satisfação, é primária em relação à satisfação da necessidade. Essa subversão conceitual permite ressituar a anorexia no campo do desejo, já que o objeto em jogo em sua formação sintomática não é o seio, e sim o "nada" como seu substituto simbólico. Isso tem consequências significativas na relação do sujeito com o Outro.

Na dialética da frustração, não é só o objeto real - seio - que assume um valor simbólico, mas principalmente a atividade oral que através da satisfação simbólica adquire uma função erotizada. Se a ênfase recai sobre a atividade da zona erógena da boca, e sobre o gozo que daí advém, então o objeto real oral pode ser qualquer um: o seio, a mamadeira e até mesmo o "nada" do comer anoréxico.

b O jogo infantil que Freud descreve em Mas allá del principio de placer ${ }^{12}$ como o Fort-Da faz parte das primeiras tentativas de simbolização das ausências da mãe. O carretel que é jogado representa esse primeiro sujeito que se constitui nesse movimento de separação. É também em favor de uma tentativa de simbolização que a criança se coloca no lugar desse objeto que satisfaz a mãe (o falo), na medida em que é a causa dessas idas e vindas da mãe. Nessa via, seu desejo vai constituir-se a partir do desejo do outro (mãe) numa relação metonímica. 
É Lacan quem chama a atenção para o fato de que a erotização da zona oral pode ir tão longe que a satisfação substituta pode ser o comer "nada" da anorexia:

[...] é possível que, para desempenhar o mesmo papel, não exista em absoluto objeto real. Trata-se, com efeito, apenas daquilo que dá lugar a uma satisfação substitutiva da saturação simbólica. Apenas isso pode explicar a verdadeira função de um sintoma como o da anorexia mental. ${ }^{14}$

Em suma, não é a atividade de comer que é negada pela criança, ela come o "nada" - "nada, isso é justamente algo que existe no plano simbólico". ${ }^{14}$ No nível oral, na medida em que houve o desmame, o seio deixa de ser objeto substitutivo para o qual se dirige o investimento. É o "nada" que ocupa seu lugar, como símbolo da perda do seio, isto é, como objeto simbólico. O comer o "nada" da anorexia funciona de acordo com essa dialética: trata-se de uma ausência saboreada, que é endereçada à mãe, de quem a criança depende inicialmente de maneira absoluta. Com essa "modalidade de recusa", a criança inverte a relação de dependência: ela faz a mãe depender dela. Consequentemente, a angústia ficará agora do lado deste Outro materno que se esforça para fornecer o objeto alimentar. Sobre essa inversão da relação de dependência, Lacan assinala:

É no nível do objeto anulado como simbólico que a criança põe em xeque a sua dependência, e precisamente alimentando-se de nada. É aí que ela [a criança] inverte sua relação de dependência, fazendo-se, por esse meio, o mestre da onipotência [...] A partir dai é ela [a mãe] que está à sua mercê,à mercê das manifestações do seu capricho. ${ }^{15}$

Se a anoréxica joga no campo simbólico, onde o Fort-Da do comer "nada" assume valor de gozo, então podemos supor que não é com programas de realimentação forçada que podemos compor um tratamento possível. Esses programas, ao modo da mãe angustiada com o não comer de sua filha, só cumprem a função de saturação do jogo simbólico. Desta forma, só reforçam o circuito da demanda no qual o Outro empanturra a criança "com a papinha sufocante daquilo que ele tem", ${ }^{16}$ enquanto esta recusa o alimento como forma de sustentar um desejo. Aqui, extraímos uma preciosa indicação clínica, no questionamento de Lacan: "Afinal de contas, a criança, ao se recusar a satisfazer a demanda da mãe, não exige que a mãe tenha um desejo fora dela [da criança], porquanto é essa via que lhe falta [à criança] rumo ao desejo?"17

A aposta do tratamento psicanalítico é que esse jogo simbólico inconsciente possa ser posto em ato na transferência, pela instituição de um espaço de fala que conte com a divisão do sujeito, implícita no sintoma. Seu objetivo não é resolver uma urgência alimentar, nem eliminar a angústia advinda daí, mas sim escutá-la promovendo o deslocamento dessa satisfação à qual o sujeito está fixado. É contando também com o desejo do analista como operador do desejo do Outro, na rota 
da assunção do desejo, que se pode fazer vacilar e dosar a angústia, que inicialmente fica localizada do lado do Outro (a mãe ou até mesmo a analista).

No caso de Laura, encontramos a tentativa de negar sua dependência ao Outro que "a leva onde quiser" através do comer "nada"; no entanto, encontramos também seu extremo apelo ao Outro em sua face eminentemente simbólica e dialetizada. A posição do objeto "nada" tão realizado, ao qual o sujeito fica muitas vezes identificado, também mostra seus efeitos na transferência. As idas e vindas, as inúmeras faltas decorrentes das internações, o pedido de não ser abandonada, até o momento em que ela assume seu desejo de continuar o tratamento: são tempos no estabelecimento da transferência que revelam o circuito da demanda operando de acordo com a dialética da frustração.

Considerando que a dialética da frustração é estruturante do desejo, é importante questionar se o sintoma anoréxico está exclusivamente relacionado à sexualidade feminina, como pode sugerir uma interpretação ingênua. Se, para alguns autores, a prevalência de casos de anorexia na adolescência estaria relacionada com a recusa dos caracteres femininos ou da feminilidade,$^{18} \mathrm{O}$ desenvolvimento proposto aponta que o que está em jogo nesses casos é a erotização da oralidade, independentemente do gênero. Para Freud, a sexualidade é mais ampla do que a sexualidade genital e se caracteriza pela mobilidade dos investimentos libidinais que podem direcionar-se tanto para a oralidade, quanto para a genitalidade, assim como para qualquer outro objeto ou parte do corpo.

Nessa linha, o regate do aspecto simbólico e inconsciente que está em jogo na anorexia descola o sintoma de sua materialidade biológica, relançando-o no campo do desejo, cuja dialética está tanto para homens quanto para mulheres. Não se trata, portanto, de um sintoma feminino por excelência, mas de uma dinâmica sintomática que comporta sua dimensão de gozo.

Partindo desse pressuposto, talvez seja possível ampliar o entendimento do crescimento dos casos de anorexia em homens, pois as exigências da atualidade e a saturação simbólica do Outro que tudo tem implicam encontrar um modo singular de sustentar seu desejo, campo fértil para sintomas como a anorexia, que atendem de modo contundente aos ideais estéticos do nosso tempo.

\section{Referências}

1. Almeida TC, Guimarães CF. Os blogs pró-Ana e a experiência da anorexia no sexo masculino. Saúde Soc. 2015; 24(3):1076-1088.

2. Freud S. Manuscrito K. 1896. In: Freud S. Obras completas. Buenos Aires: Amorrortu; 2006.

3. Freud S. Moisés e o monoteísmo. (1939[1934-38]). In: Freud S. Obras Completas. Buenos Aires: Amorrortu; 2006.

4. Oliveira RC. Gênero e corpo adolescente: considerações biomédicas e reflexões sociológicas sobre comportamento alimentar. Revista Bahia Análise \& Dados 2010; 20(4):617-628. 
5. Freud S. Rascunho G: Melancolia. (1895). In: Freud S. Obras Completas. Buenos Aires: Amorrortu; 2006.

6. Freud S. Herencia y etiologia de las neurosis. (1896) In: Freud S. Obras Completas. Buenos Aires: Amorrortu; 2006.

7. André S. O que quer uma mulher? Rio de Janeiro: Jorge Zahar; 1998.

8. Freud S. Inhibición, síntoma y angustia (1926 [1925]). In: Obras completas. Buenos Aires: Amorrortu; 2006.

9. Freud S. Inhibición, síntoma y angustia (1926 [1925]). In: Freud S. Obras Completas. Buenos Aires: Amorrortu; 2006. p. 94.

10. Freud S. Inhibición, síntoma y angustia (1926 [1925]). In: Freud S. Obras Completas. Buenos Aires: Amorrortu; 2006. p. 95.

11. Lacan J. O Seminário 4: a relação de objeto. Rio de Janeiro: Jorge Zahar; 1995.

12. Freud S. Más Allá del principio de placer (1920). In: Freud S. Obras Completas. Buenos Aires: Amorrortu; 2006.

13. Lacan J. O Seminário 4: a relação de objeto. Rio de Janeiro: Jorge Zahar; 1995. p. 186.

14. Lacan J. O Seminário 4: a relação de objeto. Rio de Janeiro: Jorge Zahar; 1995. p. 188.

15. Lacan J. O Seminário 4: a relação de objeto. Rio de Janeiro: Jorge Zahar; 1995. p. 190.

16. Lacan J. A direção do tratamento e os princípios de seu poder. In: Lacan J. Escritos. Rio de Janeiro: Jorge Zahar; 1998. p. 634.

17. Schmidt E. Mata GF. Anorexia nervosa: uma revisão. Fractal: Rev. Psicol. 2008; 20(2):387-400. 
